\title{
Nutrition Discussion Forum
}

\author{
The role of de novo lipogenesis in development of obesity in man
}

Lammert et al. (2000a) reported a marked de novo lipogenesis, both hepatic and extrahepatic, in male subjects overfed with a carbohydrate-rich diet. In that paper (Lammert et al. 2000a), we concluded that de novo lipogenesis was sufficient to account for about $40 \%$ of the increase in fat mass. We were not able to demonstrate any increase in heat production during sleep with time ( 3 weeks). This paper has directly or indirectly given rise to five contributions in the British Journal of Nutrition. They all discuss the question of energy expenditure related to overfeeding and to de novo lipogenesis, but do not pay much attention to the more important question: does de novo lipogenesis play a role in the development of obesity in man? For many years, one of numerous arguments against the role of de novo lipogenesis has been that it was unlikely to occur to any important degree, because of the considerable energy expenditure related to the synthesis of fatty acids on the basis of carbohydrate. In the following article, I shall comment on the five contributions.

Schutz (2000) described our paper as 'timely' and mentioned three innovative features of our study. (1) The design with a pair of subjects living together during the experiment ('Siamese' activity twins), one over-consuming a carbohydrate-rich diet and the other, an isoenergetic fatrich diet. In this way we compensated for our lack of measurement of total energy expenditure; we measured only energy expenditure (by direct and by indirect calorimetry) during the last $3 \mathrm{~h}$ of sleep. (2) The estimate of wholebody net de novo lipogenesis by the difference between the amount of body fat deposited and the amount of fat available for storage (intake of fat minus faecal loss of fat and minus oxidised fat). (3) The measurement of faecal losses. Schutz (2000) discussed the problem: can we believe in 'luxus consumption'? Our results (Lammert et al. 2000a) indicated that if 'luxus consumption' took place, it was not significantly different between the two groups that were overfed with carbohydrate-rich or fat-rich diets.

Astrup \& Raben (2000) recalculated the results of Lammert et al. (2000a) and stressed that we overlooked our main finding: that the carbohydrate-rich diet led to a higher loss of energy in faeces and a lower increase in fat mass than the fat-rich diet. On the basis of the high cost of de novo lipogenesis, they assumed that it is less fattening to overeat carbohydrate than fat. This is a reasonable expectation and not excluded by us, but our main findings concern de novo lipogenesis.

The reply by Lammert et al. (2000b) to the criticism of Astrup \& Raben (2000) contained critical arguments about details of the way in which the latter recalculated the results. We later calculated that we should have used two groups of forty-two subjects instead of ten subjects in order to demonstrate statistical significance in the difference in fat deposition expected by Astrup \& Raben (2000).

Chwalibog \& Thorbek (2001) then commented on our study (Lammert et al. 2000a). They found the impedance method used by us dubious for the quantitative determination of fat deposition. We did calculate total and hepatic de novo lipogenesis on the basis of our (scant) data on underwater weighing. This gave us greater values for fat deposition, so our conclusions would be the same. Chwalibog \& Thorbek (2001) refer to their own paper (Chwalibog \& Thorbek, 2000), in which they presented evidence for a substantial whole-body de novo lipogenesis in human subjects fed to satiety. Larsen (2001) discussed the study by Lammert et al. (2000a) and the paper by Chwalibog \& Thorbek (2000) in a wider context. Based on the facts and calculations cited by Larsen (2001) it can be concluded that: (1) whole-body de novo lipogenesis does take place, not only in human subjects overfed with a carbohydraterich diet, but also in human subjects consuming a diet with more than $30 \%$ energy as fat, even under conditions of weight constancy; (2) de novo lipogenesis takes place in adipose tissue as well as in the liver; (3) in countries with increasing incidence of overweight and obesity, hepatic and especially extrahepatic de novo lipogenesis will probably contribute significantly to increases in body weight, especially when sugars constitute an important part of the carbohydrate.

Finally, Acheson \& Flatt (2002) discussed the letter by Chwalibog \& Thorbek (2001) and elaborated on the energy cost of de novo lipogenesis. The former referred to calculations showing that if the synthesis of fat from glucose is accompanied by oxidation of an equivalent amount of fat, the substrate handling costs are hardly greater than when glucose is oxidized directly. We certainly need more knowledge about turnover of fat in various organs and/or tissues and at a whole-body level and of the size of extrahepatic de novo lipogenesis under various conditions. Acheson \& Flatt (2002) add that in human subjects, de novo lipogenesis is a rather limited process. This statement is not supported by the literature referred to earlier, and is especially invalid with regard to development of obesity in human subjects who overeat relative to their energy expenditure.

Lis Olesen Larsen August Krogh Institute University of Copenhagen Universitetsparken 13 DK 2100 Copenhagen Denmark 


\section{References}

Acheson KJ \& Flatt JP (2002) Minor importance of de novo lipogenesis on energy expenditure in human. British Journal of Nutrition 87, 189.

Astrup A \& Raben A (2000) Sugar as a slimming agent? British Journal of Nutrition 84, 585-587.

Chwalibog A \& Thorbek G (2000) Energy metabolism and lipogenesis in humans. Thermochimica Acta 349, 43-51.

Chwalibog A \& Thorbek G (2001) Energy expenditure by de novo lipogenesis. British Journal of Nutrition 86, 309.

Lammert O, Grunnet N, Faber P, Bjørnsbo KS, Dich J, Larsen LO, Neese RA, Hellerstein MK \& Quistorff B (2000a) Effects of isoenergetic overfeeding of either carbohydrate or fat in young men. British Journal of Nutrition 84, 233245.

Lammert O, Grunnet N, Faber P, Bjørnsbo KS, Dich J, Larsen LO \& Quistorff B (2000b) Letter to the Editors. British Journal of Nutrition 84, 943.

Larsen LO (2001) From starving lampreys and voracious toads to lipogenesis and development of obesity in human beings. In Perspectives in Comparative Endocrinology: Unity and Diversity. Proceedings of the 14th International Congress of Comparative Endocrinology, pp. 683-691 [HJT Goss, RK Rastogi, H Vaudry and R Pierantoni, editors]. Bologna: Monduzzi Editore Sp.A, Medimond Inc.

Schutz Y (2000) Human overfeeding experiments: potentials and limitations in obesity research. British Journal of Nutrition 84, $135-137$. 